\title{
A Child Rights Perspective on Intergenerational Trauma
}

\author{
Brent Bezo \\ Doctoral candidate, Department of Psychology \\ Carleton University
}

\begin{abstract}
Intergenerational trauma, conceptualized as singular past events that continue to adversely impact individuals, families, communities and nations through the generations, undermines the rights of the child, as per articles of the United Nations Convention on the Rights of the Child. Intergenerational trauma contrasts with historical trauma that encompasses multiple past traumatic and longstanding systemic events that combine to cumulatively and adversely affect individuals, families, communities and nations across generations. This article draws on evidence suggesting that intergenerational trauma deprives children of their rights to environments free of maltreatment-abuse (Articles 19) and poverty (Article 27), in addition to undermining their rights to their own culture (Article 30). Using intergenerational trauma research, it suggests that child maltreatment-abuse, poverty, and loss of culture prevent the child from obtaining the best possible health, with the latter also a right outlined in Article 24. Given the argument that the study of intergenerational trauma owes its existence to political movements, recommendations are made for researcher engagement in multi-sectoral childcentric research initiatives, in order to help realize children's rights that are undermined by intergenerational trauma and improve children's health.
\end{abstract}

Keywords: intergenerational trauma, historical trauma, children's rights, war, genocide, colonization 


\section{Introduction}

\section{Intergenerational Trauma}

In this article, I argue that intergenerational transmission of trauma undermines the rights of the child across generations. Intergenerational transmission of trauma is the phenomenon of trauma from colonization, war, or genocide that not only adversely impacts survivors, but also their descendants. The available evidence suggests that intergenerational trauma impacts multiple levels including individual health and well-being, family processes, and community and sociocultural norms across generations. In this context, generations of children born after their ancestors' traumatogenic experiences are at risk for exposure to altered family systems, community functioning and sociocultural norms, which in turn may have adverse impacts on physical and mental health (Bezo and Maggi, 2015a).

The term, intergenerational transmission of trauma, generally refers to the psychosocial, cultural, and physical health impacts on descendants of collective trauma survivors, stemming from a singular past mass traumatic event. The overlapping construct, historical trauma (Brave Heart, 1999), was introduced into the literature to explain transgenerational consequences among Indigenous communities and nations which are cumulative over time and result from multiple past traumatic events. Similar to the intergenerational trauma framework, historical trauma has conceptualized impacts to affect multiple levels including individual well-being, families, communities and sociocultural norms from generation to generation. Differing from the intergenerational trauma framework, the historical trauma paradigm not only encompasses impacts from discrete multiple past traumatic events (e.g., residential schools), but also impacts from longstanding historic systemic traumatic events that continue into the present day (e.g., racism, contaminated lands), with the latter being continual sources of revictimization. Therefore, under the historical trauma paradigm, these current persistent systemic traumatic events combine with multiple past acute events to result in increased impacts on individuals, families, and communities from generation to generation (Evans-Campbell, 2008). Conversely, the intergenerational trauma framework recognizes transgenerational impacts as remaining consistent (i.e., not necessarily increasing or decreasing over time), or even diminishing across generations. Research to date has not yet systematically investigated potential cumulative effects of historical trauma, a key consideration that differentiates historical trauma from intergenerational transmission of trauma. However, a growing body of evidence supports the 
multilevel perspectives of both the intergenerational transmission of trauma and historical frameworks in that mass trauma experienced by past generations can affect individual wellbeing, family functioning, community and sociocultural norms through the generations. Because of the similarities between frameworks, this article uses the term intergenerational trauma to signify both intergenerational transmission of trauma and transgenerational impacts stemming from historical trauma.

The intent here is to offer a child's rights perspective of intergenerational trauma rather than a full description of the intergenerational trauma literature. This approach recognizes that successive generations of children grow and develop in the aftermath of collective traumas. Historic traumatic events, themselves, are not directly transmitted across generations from survivors to future generations of children (Pat-Horenczyk, Brom, \& Vogel, 2014). Instead, an altered environment (i.e., of disrupted family, community, and sociocultural norms) is transmitted from generation to generation, which in turn has the potential to disrupt children's development and increases their immediate and long-term risk for poorer mental and physical health. Thus both the altered environments and increased risk for health stemming from intergenerational trauma undermines the rights of the child, as per the United Nations Convention on the Rights of the Child (UNCRC), which sets out the political, civil, economic, environmental, cultural, and health rights of children (United Nations, 1989).

The notion of intergenerational trauma has its roots in the trauma literature. Herman's influential ideas (1997) viewed trauma as "predictable psychological harm" (p. 3) resulting from having survived terrible events, and accepted psychiatric constructions of trauma diagnoses, but viewed them as patriarchal and restrictive. In contrast, Burstow (2003) viewed psychiatric underpinnings as androcentric and also stigmatizing, owing to the field's diagnostic labels comprised of problematic symptoms. Alternatively, Burstow suggested that problematic trauma symptoms can be reconceptualized as normal reactions or "coping skills" (p.1295) that represent "constructive ways of conducting oneself in fraught and often impossible situations" (p. 1305). In terms of contributions to the study of intergenerational trauma, this distinction is made because researchers from mental health disciplines are historically the main contributors to the field. As such, these mental health terms from the intergenerational trauma literature are used to highlight the transgenerational impacts on children. However, in highlighting the impacts of intergenerational trauma on children, the intent is not to stigmatize or blame child victims of 
intergenerational trauma as suffering and who need to be 'fixed.' Instead, as per LeFrancois and Coppock (2014), the source of trauma's impacts on children should be recognized as direct external violence. Therefore, finding solutions to the impacts of trauma requires political solutions to end or 'treat' current violence. By extension, historical violence, which may or may not be observable in the present, should also be recognized as the external source of current intergenerational trauma impacts, rather than blaming or assuming inherent deficits in nations, communities, families/parents, and individual children adversely affected from generation to generation.

\section{Intergenerational Trauma as a Child's Rights Issue}

The first section below sets out the argument that intergenerational trauma deprives children of their rights as per Articles 19, 27, 30, and 24 of the UNCRC. Specifically, Article 19 recognizes the right of the child to be protected from abuse and maltreatment while in the care of parent(s), guardians, and caregivers. Article 27 recognizes that children have the right to a material standard of living that promotes healthy physical and mental development. Article 30 sets out the rights of minority and Indigenous children to their own culture, religion, and language. Article 24 sets out the child's right for the obtainment of the highest health status. It summarizes the available evidence demonstrating that intergenerational trauma, in increasing the risk for abuse and maltreatment, poverty, and loss of culture, religion-spirituality, and language, deprives children of their rights (Articles 19, 27, and 30, respectively). Further, the first section of this paper also summarizes the available evidence from the intergenerational trauma literature that directly links transgenerational outcomes of abuse-maltreatment, poverty, and loss of culture to underperformance in mental and physical health among descendants of collective trauma survivors. In this context, intergenerational trauma also deprives the child of the best possible health, a right outlined in Article 24. Therefore, criteria for inclusion of articles in the

first section were: (i) evidence-based articles (utilizing quantitative or qualitative methods) that relate intergenerational trauma's impacts to external factors (such as poverty, loss of culture, etc.), (ii) and evidence-based articles (again utilizing quantitative or qualitative methods) that link those external factors to mental and physical health issues.

Forming the intergenerational trauma evidence-based literatures, both intergenerational transmission of trauma and historical trauma are concepts first introduced by mental health 
researchers and professionals to explain the disproportionate adverse psychological and mental health outcomes often exhibited in descendants of collective trauma survivors. Currently, and as noted above, mental health researchers and professionals in psychology and psychiatry (and to a lesser extent social work and epidemiology) were historically, and are still, the main contributors to this field of study which has since expanded to include the impacts of intergenerational trauma on physical health and social outcomes. Disciplines such as economics, education, political science, and history may have different frameworks, constructions, and approaches for defining and interpreting trauma and its long-term consequences that may therefore recognize UNCRC Articles not identified in this paper. However, as noted above, this paper considers evidence from the intergenerational trauma literature which focuses primarily on health outcomes, as well as on family processes and community well-being consequences that support the argument that intergenerational trauma undermines children's rights as per Articles 19, 27, 30, and 24 of the UNCRC. As such, this paper includes collective trauma research on the intergenerational impacts of the colonization of Indigenous peoples, the Jewish Holocaust (Shoah), the 1930s genocide of Ukrainians (Holodomor), the internment of Japanese Americans during the Second World War (WWII), and the 1993 Gaza war.

The second section of this paper discusses Judith Herman's (1997) seminal argument that the recognition and study of, and healing-treatment programs and centres for, soldier-related and sexual assault trauma were dependent on the 1970s large-scale grassroots political movements. These political movements, independent of government and the medical establishment, brought war-related and sexual assault trauma into the public consciousness as human rights issues. This awareness, in turn, led to the recognition of adverse psychological impacts of trauma, opening of rape crises centres, rape legislation and an unprecedented increase in soldier-related and sexual assault trauma research. Moreover, all of the latter took place over a very short period of time. Using a slightly different trajectory for the recognition of collective trauma instead of solely relying on grass roots campaigns, public recognition of collective trauma and its intergenerational impacts as human rights violations have involved the work of individual activists and organizations, grassroots education and awareness campaigns, school curricula, commissions and their reports, government initiatives, and researchers. However, in keeping with Herman's assertion, this paper argues the systematic study of intergenerational trauma is 
dependent on the support of political movements that legitimate collective traumas as human rights abuses.

The third section of this paper argues that in order to improve the lives of children impacted by intergenerational trauma, not only is the recognition of collective trauma and its intergenerational impacts necessary, but intergenerational trauma must also be recognized as a child rights issue. Researchers could play a greater role, via multisectoral research collaborations, to increase research in the field and contribute to child-centric evidence-based policies and programs. The goal of such policies and programs is to realize children's rights that are undermined by intergenerational trauma, in order to improve children's health and wellbeing.

\section{Intergenerational Trauma and Children's Rights: What Does the Evidence Tell Us?} Intergenerational Trauma and Child Maltreatment-Abuse

Article 19 of the UNCRC recognizes that children have the right to be protected from physical or mental violence, abuse, neglect, maltreatment and sexual abuse while in the care of parent(s), guardians, or any individual who cares for children. The available evidence suggests that intergenerational trauma increases the risk of various forms of child maltreatment in descendants of collective trauma survivors and, therefore, undermines children's rights as set out in Article 19. Investigation into the intergenerational impact of the Indian Residential Schools in Canada reveals child maltreatment as an outcome into the second and third generations. Specifically, First Nations adult children and grandchildren of Indian Residential School survivors report more lifetime abuse (as per a composite score of physical, mental, emotional and sexual abuse) than their counterparts whose parents and grandparents were non-attendees (Elias et al., 2012). Investigation into the intergenerational impact of the Holocaust on children demonstrates that adult children of Holocaust survivors were more likely to report abuse (with the exact nature of the abuse not specified) and neglect in their childhoods compared to Jewish comparison participants with no family history of the Holocaust (Lehrner et al., 2014). In addition, one Holocaust study also shows the impact of intergenerational trauma into the second and third generations, whereby adult children and grandchildren viewed their exposure to childhood neglect, in terms of lack of parental support, as an intergenerational impact of the Holocaust (Scharf \& Mayseless, 2011). 
A limitation of the maltreatment studies is their lack of reporting on the exact types of maltreatment and abuse (e.g., physical, sexual). However, the composite scores used in the maltreatment studies suggest that intergenerational trauma is a risk factor for both physical and sexual abuse, which undermines the child's right to protection from maltreatment (Article 19). A second limitation of the maltreatment studies is the lack of reporting on the perpetrators. As a result, no conclusions can be drawn as to whether the abuse was committed by parents, extended family members, neighbours, members in the community, etc.

\section{Linking child maltreatment and abuse to the right to health}

Research further suggests that child abuse and maltreatment stemming from intergenerational trauma also undermines children's right to the highest possible standard of health, with the latter recognized in Article 24. Specifically, intergenerational trauma consequences of child abuse and neglect have been shown to predict mental health adversity in descendants of collective trauma survivors. For instance, paternal exposure to the Gaza war predicted neglect and emotional abuse in their 10-12 year old Palestinian children. In turn, abuse and neglect predicted higher levels of depression and posttraumatic stress in the second generation children (Palosaari, Punamäki, Qouta, \& Diab, 2013). Holocaust research also linked child abuse, stemming from intergenerational trauma, to adverse mental and physical health outcomes. Specifically, Holocaust offspring reported more childhood emotional and sexual abuse and physical and emotional neglect compared to Jewish participants with no family history of the Holocaust. In turn, among offspring, emotional abuse, sexual abuse, emotional neglect, and physical neglect were associated with greater posttraumatic stress disorder (PTSD). In addition, emotional abuse was associated with lower levels of the hormone cortisol in adult children (Yehuda, Halligan, \& Grossman, 2001), indicative of dysregulated physiological functioning of the hypothalamus-pituitary-adrenal (HPA) axis. The health literature is consistent in showing that altered HPA axis functioning, a response to psychological stress and adversity, increases the risk for numerous diseases including cardiovascular disease, hypertension, and diabetes. Altered HPA functioning also weakens the immune system and increases illness susceptibility from viruses (McEwen, 2005). The health literature is also consistent in demonstrating that child abuse is a risk factor for physical and mental health issues later in adulthood. Pertaining to physical health, research has associated child abuse with increased neurological, 
musculoskeletal, and respiratory issues, cardiovascular disease, and gastrointestinal, metabolic disorders (Wegman \& Stetler, 2009), chronic fatigue, pain, and poorer self-rated health in adulthood (Greenfield, 2010). In general, child abuse has also been associated with adult mental health issues including depression, anxiety, mania, and drug and alcohol use (Greenfield, 2010).

\section{Intergenerational Trauma and Poverty}

Article 27 of the UNCRC recognizes that all children have the right to a standard of living that promotes the physical and mental development of the child. Research suggests that intergenerational trauma undermines this right. Specifically, intergenerational trauma results in poverty that persists across generations and affects the well-being and development of descendants of collective trauma survivors. For instance, Ukrainian genocide survivors reported that as a result of losing their homes, properties, and personal possessions that were confiscated during the genocide, an immediate onset of poverty ensued. Further, adult children and grandchildren of survivors reported that they continue to live in poverty, originally inflicted on their ancestors, but that continued to persist into their lives (Bezo and Maggi, 2017). Similarly, Gagné's (1998) case study demonstrated that the Cree First Nations citizens in Canada lost their economic independence as a result of colonization, which then led to poverty through the generations.

\section{Linking poverty to health}

As previously noted, Article 24 recognizes that children have the right to the highest possible health status. However, research suggests that poverty from intergenerational trauma undermines the possibility of attaining the best health in descendants of collective trauma survivors. For instance, Aboriginal Canadians report that colonization still impacts health at present. Specifically, colonization resulted in a loss of traditional self-sufficiency which in turn resulted in economic hardship and limits on the ability to purchase high quality healthy food, which adversely affected health (Richmond \& Ross, 2009). Similarly, adult children and grandchildren of Ukrainian genocide survivors noted that the intergenerational poverty into which they were born has adverse health consequences in terms of restricting their ability to purchase medications and pay for health care treatments (Bezo and Maggi, 2017). These collective trauma descendants' reports are congruent with findings from the health literature 
which has long recognized that poverty is linked to poorer health and increases the risk for diseases, infections, and child mortality (Marmot, 2005).

\section{Intergenerational Trauma and Cultural, Religious, and Language Rights}

Article 30 of the UNCRC recognizes that minority and Indigenous children shall not be denied the right to enjoy their own culture, practice their own religion, and use their own language. The intergenerational trauma literature demonstrates that collective traumas have resulted in loss of religious/spiritual and cultural practices, and language across generations. As a result, research suggests that subsequent generations born decades after their ancestor's traumatic experiences are deprived of their own culture, religion, and language. For instance, as a result of their internment during WWII, Japanese Americans were less likely to teach their children Japanese culture and language. Adult children of Japanese American internees held their parental internment, associated with a reluctance to pass down traditions, responsible for their loss of Japanese identity (Nagata, 1993). The forced removal and separation of Indigenous children from their families and communities via Boarding Schools in the United States (EvansCampbell, 2008) and Indian Residential Schools in Canada (Truth and Reconciliation Commission of Canada, 2015) resulted in severing language, cultural, and spiritual traditions from not only children attendees, but also their descendants. In this context, Māori of New Zealand report that lost traditions and language, stemming from colonization, had resulted in diminished Indigenous identity among today’s children (Beltrán \& Begun, 2014), while Diné children of the United States held loss of culture and traditions responsible for sadness and behavioural issues among children in their communities (Goodkind et al., 2012).

\section{Linking culture to the right to health}

The available evidence further suggests that intergenerational trauma, by depriving generations of children of their rights to their own culture and cultural practices across generations, also deprives children of their rights to the highest standard of health, with the latter

outlined in Article 24. In this context, intergenerational trauma studies have linked loss of culture to poorer health and risky health behaviours that negatively impact health. For instance, Aboriginal Canadians view the loss of culture and traditional ways of life stemming from colonization as having been supplanted by a sedentary life-style and the consumption of unhealthy processed foods, leading, in turn, to increased rates of obesity and diabetes (Richmond \& Ross, 2009). Indigenous Diné report increased alcohol use as an intergenerational response to 
colonization that altered cultural norms related to health and well-being. Specifically, widespread alcohol use was held responsible for increasing social violence, which in turn resulted in increased violent deaths. Similarly, descendants of Ukrainian genocide survivors report that the 1930s genocide adversely impacted their culture with negative health consequences. Specifically, men began using alcohol as a coping strategy in response to the 1930s genocide, a behaviour that subsequently took root in the culture of Ukraine and persisted across generations. In turn, increased cultural acceptance of alcohol use resulted in a greater acceptance of risky health behaviours in general among subsequent generations of youth. In turn, greater acceptance of risky health behaviours was held responsible for high rates of drug use and acquired immune deficiency syndrome (AIDS) prevalence in Ukraine (Bezo and Maggi, 2015a).

By linking loss of culture to poorer health, culture can be viewed as a determinant of health among descendants of collective trauma survivors. In this context, culture likely establishes which factors are affiliated with children's abilities to cope with stress and the risk of, or protection against, disease. Therefore, in order to fully realize the right of the child to enjoy the highest possible status of health as outlined in Article 24, State Parties also need to fulfill Article 30 which sets out children's rights to their own culture, religion, and language. This argument is congruent with Beltrán \& Begun (2014) noting that among Indigenous communities, culture and cultural identity improve health outcomes by improving self-esteem and coping with stress, in addition to buffering against depression. The notion of increasing children's rights to their own culture, religion, and language as a means to improving health status among descendants is also consistent with the health literature that suggests that increased identification with ethnicity identity is associated with better health, especially among minority children (Greig, 2003). Ethnic identity, in terms of having a clear sense of ethnic background, having a strong attachment to one's ethnic group, and having participated in one's own cultural activities is considered to fully develop during the adolescent years (Roberts et al., 1999). Further the health literature demonstrates that strong ethnic identity is related to increased coping abilities, mastery, self-esteem, optimism, and decreased depression among adolescents from diverse ethnocultural groups. Ethnic identity has also been positively associated with self-rated physical health (Ai, Aisenberg, Weiss, \& Salazar, 2014). Similarly, higher religiosity and spirituality have been linked to lower rates of depression, suicide, substance abuse, and stress-related disorders (Bonelli \& Koenig, 2013). 


\section{Intergenerational Trauma Research Depends on Public Movements}

There is a small but growing body of evidence that has linked intergenerational trauma stemming from war, genocide and colonization to adverse outcomes in descendants of survivors. In comparison, the current trauma literature is replete with studies on the impacts of trauma on survivors, for example, of soldier-related war combat and sexual assault. However, Herman (1997) asserts that the development of the soldier and sexual assault trauma literatures owe their existence to human rights movements. Specifically, political movements were required to negate social processes of denial, silencing and forgetting surrounding trauma in order to legitimate the pursuit of trauma study, public discussion of trauma, and healing-treatment programs for trauma. Herman chronicles how young men's rights as soldiers and women's rights could only be recognized and legitimized as human rights in environments where political movements challenged the acceptability of young men sacrificed in war and the insubordination of women, respectively. Specifically, in the early 1970s, Vietnam War veterans organized against the war to challenge the "claim of a just war" (p. 26) and "murder in the name of virtue" (p. 27), which added credibility to the growing anti-war movement and resulted in the unprecedented recognition of psychological trauma as a consequence of war. As a result, posttraumatic stress disorder was recognized as a debilitating condition afflicting war veterans. Similarly, a political movement that challenged the acceptability of the subordination of women was a precondition for fostering the study and treatment of trauma from sexual assault. Women's movement campaigns increased public awareness of rape as violence in the 1970s. As a result, rape research centres, rape crises centres opened, and rape legislation was enacted. Lastly, Herman notes that both the veterans' and women's movements were organized outside of, but pressured, government and the medical establishment for change. By extending Herman's arguments to the collective and intergenerational trauma contexts, the systematic study of intergenerational trauma also appears to be dependent on public movements, as discussed below.

According to Herman (1997), the earlier recognition of the Holocaust in 1960s popular discourse and culture compared to other mass traumas (Kirmayer, Gone, Moses, 2014) was essential for facilitating and legitimating the study of the intergenerational consequences of the Holocaust. To this end, the first reports of intergenerational mental health impacts of Holocaust trauma appeared in the literature in 1966 (Rakoff, Sigal, \& Epstein, 1966) approximating Herman's prescribed timelines (1997) whereby public recognition preceded research in the field. 
For the next 50 years, studies on intergenerational trauma from the Holocaust have continued to appear in the scientific literature.

In the 1980s, the seeking of redress resulted in the subsequent acknowledgement of wrongdoing by the US government and payments to former Japanese American internees started in 1990. The latter political movement and redress increased public discourse of the Japanese American collective trauma experience (Nagata \& Cheng, 2003) and was followed by the first published reports of the intergenerational consequences of the Japanese American internment experience in the literature (Nagata, 1993; 1998), a trend consistent with Herman's argument that public movements act as an impetus for increased study.

According to Greenwood (2016), the work of the Royal Commission on Aboriginal Peoples and its 1996 Report resulted in a turning point in Canada by increasing public awareness of, and directing media attention to, the abuses inflicted on Indigenous peoples (Greenwood, 2016; Hurley \& Wherrett, 2000). The Commission's findings highlighted the unethical forced assimilation of Indigenous peoples and its impacts into subsequent generations (Royal Commission on Aboriginal Peoples, 1996). At the same time, during the mid-1990s, government-funded early childhood programs that emphasized Indigenous languages and culture as part of collective continuity also emerged in Canada (Greenwood, 2016). Greenwood (2016) further elaborated how the earlier work of the Royal Commission on Aboriginal Peoples and its findings fostered a climate that led to the Indian Residential Schools Settlement Agreement in 2006 and the government-formed Truth and Reconciliation Commission in 2008. According to Herman, the public awareness surrounding these events and programs would have helped to legitimate colonization-related trauma and its intergenerational impacts as human rights violations, which in turn would legitimate study on the topic. However, differing from Herman's precepts of grassroots-only movements (1997), government initiatives also helped to increase public awareness of the impacts of colonization in Canada (Greenwood, 2016). However, consistent with Herman's assertion, public awareness did precede the first empirical investigations into the health impacts of colonization, in terms of associating the Indian Residential Schools (IRS) with increased depression symptoms (Bombay, Matheson, \& Anisman) in 2011, and suicidality (Elias) in 2012, among descendants of IRS survivors who were not IRS attendees. 
More recently, in the 2000s, numerous countries, including Canada, recognized the 1930s forced-famine (i.e., the Holodomor) committed against Ukrainians as genocide which brought unprecedented international recognition to that collective trauma (Embassy of Ukraine to Canada, 2012). Since the mid-2000s, Canada has been a leader in bringing Holodomor awareness into the public consciousness. For instance, in the mid-2000s, Holodomor education and awareness was integrated into the Manitoba public school curriculum (Manitoba Education and Training, 2017). In 2014, the Holodomor Research and Education Consortium (2017), an initiative of the University of Alberta, was formed to increase public awareness and fund the study of the Holodomor. By 2015, traveling Holodomor education and awareness tours, funded by government and a private foundation and organized by a grass roots initiative, commenced in Canada (Holodomor National Awareness Tour, 2015). Beginning in 2015, the first studies on intergenerational trauma from the Holodomor genocide began to appear in the international academic literature and were reported by Canadian researchers (Bezo and Maggi, 2015a; 2015b). Again, this trend is consistent with Herman's assertion that public awareness and movements act as an impetus for increased study. However, differing from Herman's tenets of grassroots-only movements, independent of government and institutions, (1997), the Holodomor initiatives involved government, universities, organizations, private foundations and citizens working together to increase public awareness of the Holodomor.

\section{Moving Forward: Collaborative Efforts to Recognize Intergenerational Trauma as a Child Rights Issue}

Based on the available research, an argument can be made that intergenerational trauma deprives children of the rights to freedom from maltreatment and abuse (as per Article 19 of the UNCRC), a material standard of living (as per Article 27 of the UNCRC), and their own culture, religion, and language (as per Article 30 of the UNCRC). Research further suggests that these deprived rights, in turn, undermine the child's right to the highest attainable health standard (as per Article 24 of the UNCRC). Further, this paper compared Herman's assertion that the systematic study of war combat and sexual assault trauma was dependent on political movements to the scenario of collective trauma and its intergenerational impacts. The current context of political movements and intergenerational trauma do not reflect Herman's assertion in that only grassroots-level individuals and organizations, to the exclusion of government and institutional involvement, foment public awareness (1997). In contrast, as noted above, collaboration among 
grassroots-level individuals and organizations, government, universities, non-profit organizations, and private foundations has increased collective trauma public awareness. In this respect, a social innovation argument can be made that the trend of multiple actors striving for social justice vis-à-vis advocacy and social change has increased public awareness of collective trauma and its intergenerational impacts as human rights violations (Moulaert, MacCallum, Mehmood, \& Hamdouch, 2013). Social innovation theory also helps to describe social movements with their mobilization-participation processes and outcomes which arise whenever adversity related to poverty, exclusion, segregation deprivation and other issues of inequality cannot be solved through the traditional routes of public and private action. According to social innovation theory, the involvement of non-profit and non-governmental organizations, also known as the third sector, is important in affecting change as these more closely reflect grassroots civil society at the neighbourhood and community levels, as opposed to top-down hierarchical public and private power structures (Martinelli, 2013). Social innovation theory also asserts that government can help social movements succeed or undermine them (Mulgan, Tucker, Ali, \& Sanders, 2007). Arguably, both the third sector and government have therefore helped to increase public awareness of intergenerational trauma, as noted above, at least in some cases.

The emergence of international trauma studies in the scientific literature following increased public discourse and awareness of collective trauma is congruent with Herman's argument. Herman asserted that the wide-scale activism of the 1970s resulted in the recognition of, and treatment-healing programs for, veteran and sexual assault trauma in a short period of time. Arguably, the 1970s era in North America and Western Europe was a unique moment in history that ushered in unprecedented social change. In comparison, the realization of healing programs and initiatives for intergenerational trauma appears to be occurring at a slower pace. Pertaining specifically to the Indigenous context in Canada, Greenwood (2016) echoes this latter sentiment by quoting the former chair of the Truth and Reconciliation Commission, Senator Murray Sinclair, who one year after the Commission's 2015 final report noted that: "to suggest that there has been progress would be to suggest that we have achieved change, but we're on the beginning edge of starting to change things" (p. 17).

How can researchers play a role in 'starting to change things?' In the traditional sense, researchers could play a role in systematically studying the impacts of intergenerational trauma, 
and their findings could be used to inform evidence-based policies and programs. However, the collaborative environment, responsible for increasing public awareness of collective trauma, suggests that the present context is also apt for researchers to take a more active role in developing collaborative research initiatives with government, organizations, and representatives and stakeholders from communities with histories of intergenerational trauma, as per the social innovation approach. Specifically, community-based participatory action research (Whyte, Davydd, Lazes, 1990) that promotes equal relationships and reciprocal learning among researchers and communities could be used as a guiding model. Researchers, community members and other stakeholders, in jointly developing and implementing research projects, along with the dissemination of results, could inform evidence-based policies and culturally appropriate treatments and programs that make sense to the communities themselves.

Such multisectoral collaborative research initiatives could help find solutions to health vulnerabilities among communities, groups, and populations with histories of collective traumas, when underlying health determinants (i.e., loss of culture, maltreatment, poverty) are known. Collaborative research projects could also help identify other intergenerational trauma-related factors that undermine health. However, as Million (2014) notes, mental and physical health vulnerabilities should not be viewed as 'problems' in collective trauma descendants. Instead, Chrisjohn and McKay (2017) assert that adverse health outcomes are normal reactions to social, economic and political forces caused by current or past violence and oppression. Hence, nothing is inherently wrong, for example, with Indigenous peoples who have high suicide rates, as the latter is a reaction to past and on-going colonization, which in turn causes hopelessness among the colonized who have lost their rights, way of life, and lands. Similarly, at the family level, Blackstock and Trocmé (2005) argue that the continued disproportionate removal of Aboriginal children from their parents in Canada due to neglect, stems from the legacy of residential schools having separated children from their parents and communities as well as continued external impacts of colonization such as poverty and inadequate housing. In this context, a 'problemcentered' approach runs the risk of blaming the victims and, hence, retraumatizing children and parents who are separated due to child neglect stemming from intergenerational trauma. In general, a 'problem-centered' approach is also more likely to blame and, therefore, retraumatize individuals, parents, families, and communities affected by intergenerational trauma. As an alternative to the 'problem-centred' approach, Million (2014) notes how Indigenous health and 
social security have been reconceptualized as a 'secure' way of life that produces overall human well-being and prosperity, an approach that requires more than financial resources and programs. Further, Chrisjohn and McKay (2017) assert that sociopolitical solutions that resolve land claims, past wrongs, and economic instability, for example, would ultimately lead to better health among Indigenous peoples in Canada, in addition to improving their family and community well-being. By extension, multisectoral collaborative research initiatives that strive for sociopolitical solutions would be more successful in improving the health and well-being of individuals, families and communities affected by intergenerational trauma. In this context and as Rabia, Saleh, and Giacaman (2014) argue, resolving current and past violence requires sociopolitical solutions that provide support to families and communities, as opposed to treating children. Researchers could play a role in developing such solutions.

Most importantly, multisectoral participatory research collaborations should involve children and youth as co-researchers. Such an approach is important when considering intergenerational trauma undermining children's rights as outlined above. Therefore, in addition to helping reveal which additional intergenerational trauma factors might undermine their rights (and therefore their health and well-being), involving children would also increase the likelihood of developing child-centric evidence-based policies and programs designed to target factors that undermine the rights of the child. In this regard, Indigenous children and youth have already demonstrated leadership by participating in a landmark human rights case that found the Canadian government guilty of racial discrimination (King, Wattam, \& Blackstock, 2016). By extension, children and youth leadership could also guide research initiatives. From a developmental perspective, successive generations of children grow and develop in 'intergenerational trauma environments,' in which their undermined rights have adverse consequences for their health and well-being. Therefore, intergenerational trauma research initiatives that aim to inform evidence-based policies, programs, and sociopolitical solutions, from a child's rights perspective, could help to provide blueprints for reducing or even eliminating the external impacts of intergenerational trauma (i.e., such as reducing poverty, supporting the rebuilding of culture, and supporting families in raising children), which in turn would likely result in better health among child descendants of collective trauma survivors. A reduction, or ideally, the elimination of external impacts stemming from intergenerational trauma would help to prevent the exposure of future generations of children to intergenerational factors 
responsible for undermining their rights and health. In turn, prevention of exposure to external impacts, via a child's rights approach, might help to 'break the cycle' of intergenerational trauma.

\section{References}

Ai, A., Aisenberg, E., Weiss, S. I., \& Salazar, D. (2014). Racial/ethnic identity and subjective physical and mental health of Latino Americans: An asset within? American Journal of Community Psychology, 53, 173-184. doi:10.1007/s10464-014-9635-5

Bezo, B. \& Maggi, S. (2015a). Living in 'survival mode:' The intergenerational transmission of trauma from the Holodomor genocide of 1932-1933 in Ukraine. Social Science and Medicine, 134, 87-94. doi.org/10.1016/j.socscimed.2015.04.009

Bezo, B. \& Maggi, S. (2015b). The intergenerational impact of the Holodomor genocide on gender roles, expectations and performance: The Ukrainian experience. Annals of Psychiatry and Mental Health, 3(3), 1-4. Retrieved from https://www.jscimedcentral.com/Psychiatry/psychiatry-3-1030.pdf

Bezo, B. \& Maggi, S. (2017). Intergenerational perceptions of mass trauma's impact on physical health and well-being. Psychological Trauma: Theory, Research, Practice, and Policy. No pagination specified. http://dx.doi.org/10.1037/tra0000284

Beltrán, R. \& Begun, S. (2014). "It is medicine": Narratives of healing from the Aotearoa digital storytelling as Indigenous media project (ADSIMP). Psychology and Developing Societies, 26(2), 155-179. doi: 10.1177/0971333614549137

Blackstock, C. \& Trocmé, N. (2005). Community-based child welfare for aboriginal children: Supporting resilience through structural change. Social Policy Journal of New Zealand, 24, 12-33. Retrieved from https://www.msd.govt.nz/documents/about-msd-and-ourwork/publications-resources/journals-and-magazines/social-policy-journal/spj24/24pages12-33.pdf

Bombay, A., Matheson, \& Anisman, (2011). The impact of stressors on second generation Indian residential school survivors. Transcultural Psychiatry, 48(4), 367-391. doi: $10.1177 / 1363461511410240$

Brave Heart, M. Y. (1999). Gender differences in the historical trauma response among the Lakota. Journal of Health and Social Policy, 10(4), 1-21. doi: 10.1300/J045v10n04_01 
Burstow, B. (2003). Toward a radical understanding of trauma and trauma work. Violence Against Women, 9(11), 1293-1317. doi:10.1177/1077801203255555

Chrisjohn, R. D. \& McKay, S. M. (2017). Dying to please you: Indigenous suicide in contemporary Canada. Penticton, B.C.: Theytus Books.

Elias, B., Mignone, J., Hall, M., Hong, S. P. Hart, L., \&Sareen, J. (2012). Trauma and suicide behaviour histories among a Canadian indigenous population: An empirical exploration of the potential role of Canada's residential school system. Social Science and Medicine, 74, 1560-1569. doi:10.1016/j.socscimed.2012.01.026

Embassy of Ukraine to Canada (2012). International recognition of the Holodomor. Retrieved from http://canada.mfa.gov.ua/en/ukraine-\%D1\%81\%D0\%B0/holodomorremembrance/holodomor-international-recognition

Evans-Campbell, T. (2008). Historical trauma in American Indian/Native Alaska communities: A multilevel framework for exploring impacts on individuals, families, and communities. Journal of Interpersonal Violence, 23(3), 316-338. doi:10.1177/0886260507312290

Gagné, M. (1998) The role of dependency and colonialism in generating trauma in First Nations citizens.InY.Danieli (Ed.), International handbook of multigenerational legacies of trauma(pp. 355-372). New York: Plenum Press.

Goodkind, J. R., Hess, J. M., Gorman, B., Parker, D. P. (2012). We're still in a struggle”: Diné resilience, survival, historical trauma, and healing. Qualitative Health Research, 22(8), 1019-1036.doi:10.1177/1049732312450324

Greenfield, E. A. (2016). Child abuse as a life-course social determinant of adult health. Maturitas, 66, 51-5. doi:10.1016/j.maturitas.2010.02.002

Greenwood, M. (2016). Language, culture, and early childhood: Indigenous children's rights in a time of transformation. Canadian Journal of Children's Rights, 3(1), 17-31. Retrieved from https://journals.carleton.ca/cjcr/index.php/cjcr/article/view/95/147

Greig, R. (2003). Ethnic identity development: Implications for mental health in AfricanAmericans and Hispanic adolescents. Issues in Mental Health Nursing, 24, 317-331. doi:10.1080/01612840390160810

Herman, J. L. (1997). Trauma and recovery: The aftermath of violence - from domestic abuse to political terror. New York: Basic Books. 
Holodomor National Awareness Tour (2015). Press Release. Retrieved from https://www.cufoundation.ca/files/HolodomorBusPressReleaseJuly3-2015.pdf

Holodomor Research and Education Consortium (2017). About us. Retrieved from http://holodomor.ca/about-us/

Hurley, M. C., \& Wherrett, J. (2000). In brief on the Report of the Royal Commission on Aboriginal Peoples. Ottawa, ON: Parliamentary Research Branch, Library of Parliament. Retrieved from http://publications.gc.ca/collections/Collection-R/LoPBdP/EB-e/prb9924e.pdf

Kirmayer, L. J., Gone, J. P., \& Moses, J. (2014). Rethinking Historical Trauma. Transcultural Psychiatry, 51(3), 299-319. doi:10.1177/1363461514536358

LeFrancois, B. A. \& Coppock, V. (2014). Psychiatrised children and their rights. Children \& Society, 28, 165-171. doi:10.1111/chso.12082

Lehrner, A., Bierer, L. M., Passarelli, V., Pratchett, L. C., Flory, J., Bader, H. N., ...Yehuda, R. (2014). Maternal PTSD associates with greater glucorticoid sensitivity in offspring of Holocaust survivors. Psychoneuroendocrinology, 40, 213-220. doi: 10.1016/j.psyneuen.2013.11.019

Manitoba Education and Training (2017). Diversity Education: Holodomor and Education and Awareness. http://www.edu.gov.mb.ca/k12/cur/multic/holodomor.html

Marmot, M. (2005). Social determinants of health inequalities. Lancet, 365, 1099-104. doi: http://dx.doi.org/10.1016/S0140-6736(05)71146-6

Martinelli, F. (2013). Learning from case studies of social innovation in the field of social services: Creatively balancing top-down universalism with bottom-up democracy. In F. Moulaert, D. MacCallum, A. Mehmood, \& A. Hamdouch (Eds.), The international handbook on social innovation: Collective action, social learning and transdisciplinary research (pp. 346-360). Northampton, MA: Edward Elgar.

McEwen, B. S. (2005). Stressed or stressed out: What is the difference? Journal of Psychiatry and Neuroscience, 30(5), 315-318. Retrieved from https://jpn.ca/wpcontent/uploads/2014/04/30-5-315.pdf

Million, D. (2013). Therapeutic nations: Healing in the age of Indigenous human rights. University of Arizona Press. 
Moulaert, F., MacCallum, D., Mehmood, A., \& Hamdouch, A. (2013). General introduction: The return of social innovation as a scientific concept and a social practice. In F. Moulaert, D. MacCallum, A. Mehmood, \& A. Hamdouch (Eds.), The international handbook on social innovation: Collective action, social learning and transdisciplinary research (pp. 1-6). Northampton, MA: Edward Elgar.

Mulgan, G., Tucker, S., Ali, R., \& Sanders, B. (2007). Social innovation: What it is, why it matters and how it can be accelerated - Oxford Said Business School Working Paper. London, UK: The Basingstone Press. Retrieved from https://www.sbs.ox.ac.uk/sites/default/files/Skoll_Centre/Docs/Social\%20Innovation\%20 \%20What $\% 20$ it $\% 20$ is, $\% 20$ why $\% 20$ it $\% 20$ matters $\% 20 \& \% 20$ how $\% 20$ it $\% 20$ can $\% 20$ be $\% 2$ 0accelerated.pdf

Nagata, D. K. (1998). Intergenerational effects of the Japanese American internment. In Y. Danieli (Ed.), International handbook of multigenerational legacies of trauma (pp. 125139). New York: Plenum Press.

Nagata, D. K. (1993). Legacy of injustice: Exploring the cross-cultural impact of the Japanese American internment. New York: Plenum Press.

Nagata, D. K., and Cheng, W. J. Y. (2003). Intergenerational communication of race-related trauma by Japanese American former internees. American Journal of Orthopsychiatry, 73(3), 266-278. doi:10.1037/0002-9432.73.3.266

Palosaari, E., Punamäki, R., Qouta, S.,\&Diab, M. (2013). Intergenerational effects of war trauma among Palestinian families mediated via psychological maltreatment. Child Abuse \& Neglect, 37, 955-968. doi:10.1016/j.chiabu.2013.04.006

Pat-Horenczyk, R., Brom, D., \& Vogel, J. M. (2014). Helping children cope with trauma: Inidividual, family, and community perspectives. Newbury Park, California: Routledge, Taylor and Francis Group.

Rabaia, Y., Saleh, M. H., \& Giacaman, R. (2014). Sick or sad? Supporting Palestinian children living in conditions of chronic political violence. Children \& Society, 28(3), 172-181. doi:10.1111/chso.12061

Rakoff, V., Sigal, J., \& Epstein, N. (1966). Children and families of concentration camp survivors. Canada Mental Health, 14, 24-26. 
Richmond, C. A. M. \& Ross, N. A. (2009). The determinants of First Nation and Inuit health: A critical population health approach. Health and Place, 15(2), 403-411. doi:10.1016/j.healthplace.2008.07.004

Royal Commission on Aboriginal Peoples. (1996). Report of the Royal Commission on Aboriginal Peoples. Ottawa, ON: Government of Canada, Minister of Supply and Services.

Scharf, M. \& Mayseless, O. (2011). Disorganizing experiences in second- and third-generation Holocaust survivors. Qualitative Health Research, 21(11), 1539-1553. doi:10.1177/1049732340393747

Truth and Reconciliation Commission of Canada. (2015). Honouring the truth, reconciling for the future: Summary of the final report of the truth and reconciliation commission of Canada. Retrieved from: http://www.trc.ca/websites/trcinstitution/File/2015/Findings/Exec_Summary_2015_05_3 1_web_o.pdf

United Nations. (1989). Convention on the rights of the child. New York: United Nations. Retreived from http://www.ohchr.org/EN/ProfessionalInterest/Pages/CRC.aspx

Wegman, H. L. \& Stetler, C. (2009). A meta-analytic review of the effects of childhood abuse on medical outcomes in adulthood. Psychosomatic Medicine, 71(8), 805-812. doi:10.1097/PSY.0b013e3181bb2b46.

Whyte, W. F., Davydd G., \& Lazes, P. (1990). Participatory action research: Through practice to science in social research. In William F. Whyte (Ed.), Participatory action research (pp. 19-54). Newbury Park, California: Sage Publications.

Yehuda, R. Halligan, S. L., \& Grossman, R. (2001). Childhood trauma and risk for PTSD: Relationship to intergenerational effects of trauma, parental PTSD and cortisol excretion. Development and Psychopathology, 13, 733-753. Retrieved from https://www.cambridge.org/core/journals/development-andpsychopathology/article/childhood-trauma-and-risk-for-ptsd-relationship-tointergenerational-effects-of-trauma-parental-ptsd-and-cortisolexcretion/D88BB404705E15EA252DD7AC90C37EB1 